\title{
Understanding Reversal Theory: Six Critical Questions
}

\author{
Michael J. Apter \\ Apter Research, LLC
}

\begin{abstract}
The aim of this paper is to discuss reversal theory in a general way that brings out its key features and places it in the broadest context. What is the central idea of the theory? What is its essence? What kind of theory is it? How does it differ from other theories? Where did it come from in psychology and philosophy? Where might it be going? Is it scientific? How can it be applied? In short: What's it all about? This discussion is organized around six critical questions that raise all these issues. A key conclusion is that reversal theory is a type of paradigm that attempts to be falsifiable and that constitutes a progressive research program. The paper concludes that reversal theory has much that is new to offer psychology.
\end{abstract}

Keywords: falsifiability, motivational state, reversal, reversal theory, philosophy of science

In this paper I am going to examine reversal theory in the very broadest context and see how best it can be characterized for people who are not familiar with it. I am going to do this in terms of six critical questions - questions that are critical both in the sense of being skeptical and in the sense of being crucial to our understanding of the nature of the theory. In doing so I shall make reference to certain aspects of the history of psychology and the philosophy of science.

\section{Question 1: What is the essence of reversal theory?}

Imagine you are a researcher. You have felt some attraction to the little you have learned about reversal theory, but you want to know whether to bother to find out more. How can you tell what are the foundational insights and what are derivatives: applications, deductions, operationalizations, and so on? How can you come up with your own research question and assess whether it is in the spirit of reversal theory?

One obvious way to find out what reversal theory posits is to look at the set of propositions, making up a hypotheticodeductive system, presented in the chapter that appeared in the APA collection of review papers (Apter, 2001a). This consisted of 84 propositions arranged in hierarchical order representing five different levels of generality. As a document, this can serve the purpose of helping to make the theory amenable to systematic testing, and open to the possibility of falsification (Popper, 1968). The attempt in this set of propositions was to be both meticulous and comprehensive. Few other psychological theories have attempted to

Correspondence concerning this article should be addressed to Michael J. Apter, 530 Audubon Drive, Ruston, LA 71270 U.S.A. E-mail: mjapter@aol.com meet such strict formal conditions. The only obvious other example is Clark Hull's hypothetico-deductive learning theory, which consisted in its final version of 17 postulates and 17 corollaries (Hull, 1952), intended to explain every type of learning, and learning phenomenon, at least in rats.

As a systematic statement of the theory, the 84 propositions constitute a useful reference document. But as an introduction to the theory for someone who knows little about it, it is an undoubted failure, because it is difficult to see what holds it all together - to know what is the wood and what are the trees. An early 12-proposition version is more helpful in this respect (Apter, 1981). A set of ten statements are to be found in Apter (2005). But let us see if we can go beyond these sets of statements and make an even simpler and more accessible statement that gets at the fundamentals rather than the details. In fact, could we get the essence of reversal theory across in a single sentence - a kind of irreducible minimum?

The single sentence that most people, including nonpsychologists, seem to find easiest to grasp is something along the following lines: Reversal theory points out that our personalities, far from being stable, are often changing and inconsistent, so that each of us is a different person at different times, often over relatively short periods of time. This is an introduction in terms of personality, and it achieves this within a single sentence - albeit a rather long sentence. Then we can add, if allowed another sentence, something like: This makes the idea of stable traits rather problematic and limiting.

We could have started with a statement about motivation, along the lines that psychological motivations come in opposites, so that change involves reversing between them. There are opposite motives that alternate has to be as succinct a definition of reversal theory as it possible to have, but it does not convey a lot to the non-psychologist about its signifi- 
cance. My experience is that starting with the concept of motivation is more abstract and less helpful in explaining the theory in a few words than starting with personality. And it is certainly simpler than starting with arousal or with the emotions. To complete the introduction at this minimalist level it is probably necessary to add that each motivation determines the way that we see the world while it is active. In other words, motivation determines meaning, and, since motivation changes over time, the meaning of situations changes over time too. We can conclude that: Reversal theory attempts to make sense of our actions in terms of the opposite things that we want at different times and the inconsistent ways of seeing the world that these opposing wants give rise to.

This says nothing about how many states there are, or which ones, and it includes no reference to a number of important concepts like the sixteen emotions, dominance, satiation, focus-change, effort, and so on. But these can be seen as the "working out" of the basic insight. What these defining statements do is to establish the bedrock of the theory: they say what kind of theory it is.

\section{Question 2: What is the reversal theory approach?}

To be counted as reversal theory research, in whatever field, one might suggest that all the following criteria should apply. These criteria do not in any way restrict the topics that can be addressed, or the hypotheses than can be tested, but only the way in which they are dealt with, both theoretically and methodologically. This should not be taken to imply that research that does not include all four of these elements is not worth doing, but only that it might be arguable whether, strictly, it could be seen as reversal theory research.

- The motivational requirement. The research must involve the manipulation, identification, or measurement of at least one of the four pairs of motivational states identified in the theory, or some other reversal theory concept such as cognitive synergy, satiation, or effort stress.

- The phenomenological requirement. The research must refer directly or implicitly to subjective mental life. If there is also objective reference to behavior, physiology, and neurology. then this must be connected in some way to mental life, and to the meanings that we assign to our actions.

- The reversal requirement. The research should be sensitive to the possibility of motives within a pair alternating over time, i.e. reversing.

- The temporal requirement. There must be a temporal element to the research, requiring the measurement of changes over time or at least making reference to tendencies over time. The research must be based on the assumption that personality is at some level inconsistent.

This might seem like a lot to demand, but it is less than it seems because the items imply each other, and can to some extent be deduced from each other.
Methodologically, nothing is excluded, and various techniques have been used in reversal theory research: psychometric, experimental, case history, archival. But of these, it is clear that psychometric studies have predominated.

There is no attempt here to create a straightjacket, but simply to make clear how reversal theory differs from other theories and what makes it distinctive. Nor does it mean that reversal theory cannot be combined with other theories in particular pieces of research, and in fact its generality helps to make it a theory with strong integrative possibilities.

Note that the theory cannot be easily defined in terms of subject-matter areas. There are no limits and although there are favorite topics, like smoking cessation or sport preference, the theory can be applied in almost any area. Indeed, it has already been applied, in one way or another, in many apparently unrelated areas. These include: anxiety, depression, addiction, design, aesthetics, humor, religion, antique collecting, military combat, creativity, teaching, leadership, corporate culture, sexual behavior, crime, rape, risk-taking, and so on.

\section{Question 3: What are the antecedents of reversal theory?}

It has been said that each new theory in science creates its own antecedents. Looking back, what can we see as being some of the more notable earlier psychological ideas that have been assimilated into reversal theory? In what follows, I am listing those antecedents of which I am aware in my own work on reversal theory, but others may see other relationships, especially in relation to their own work using the theory.

\section{Philosophical}

Firstly, the theory is phenomenological, in the loose Anglo-American sense of being concerned, wholly or in part, with subjective experience, and to the meanings that we impart to our experiences. It does not necessarily follow the specific ideas of the philosopher Husserl, who invented the term "phenomenology" in the early twentieth century, but it does follow him in taking subjective mental life as open to systematic investigation. Developing from Descartes, Husserl saw the whole of science as being grounded in the subjective meanings that underlie objective measurement. In his view, we only get certainty with subjectivity, not objectivity (see Husserl, 1967, 1977). Reversal theory does not necessarily take this epistemological position, but it does emphasize subjective meaning in its explanations and predictions.

Reversal theory is not only phenomenological in the sense just indicated, but also structural, hence the term given to describe its general orientation: "structural phenomenology." The term highlights the notion that "Mental life has structure" and this has been presented as the very first proposition of reversal theory (Apter,1982; 2001a, p.39). 
In structuralism, the meaning of events, objects, and so on, resides as much in what they are not as in what they are. It is structural in seeing meanings as emerging from oppositions, as shown in the classic work on language of the linguist De Saussure (1959) and in the observations of primitive tribes by the anthropologist Claude Levi-Strauss (1966), including making sense of their myth systems, their family relationships and their cooking menus. All this gave rise to the general orientation of "Structuralism," which was a dominating force in the human and social sciences in the $1950 \mathrm{~s}$ and 60s. Reversal theory was strongly influenced by this, and especially by the idea of meaning emerging from binary oppositions. Thus "playful" derives its meaning in part from being the opposite of "serious," and vice-versa. The basic structure of the reversal theory model is based on oppositional relationships.

The term "structural" however, does not bring out the dynamic aspect of experience. In this respect there is another orientation in philosophy that better expresses the endlessly changing quality of behavior and experience. This is "Process philosophy." Without contradicting structuralism, it is possible to see reversal theory as based on the same fundamental insight as process philosophy. In classical metaphysics, also referred to as "substance metaphysics," the universe is seen as made up of static and unchanging essences. In this view, a view that goes back to Plato and Aristotle, change is seen as accidental and superficial. In the nineteenth and twentieth centuries the contrasting process view was adopted by some philosophers, notably Alfred North Whitehead (1929), to the effect that the essence of the universe is not permanence but change. An expression of this in psychology was William James' famous phrase the "stream of consciousness" (James, 1890). Reversal theory, then, is an offshoot of process philosophy. By contrast, trait theory, in emphasizing the endurance and static nature of traits, falls on the classical side of the metaphysical split.

\section{Psychological systems}

Reversal theory certainly does not fall into any of the normal text book categories such as Behaviorist, Psychoanalytic, Cognitive, Humanistic, or Discursive, so it cannot be seen as emerging from any one of these traditions, although it has complex relationships with them all (Cramer, 2013). At the same time, nothing appears from nowhere, and reversal theory does have antecedents. It is just that these are rather widespread, need tracking down in different disciplines, and do not imply that the theory belongs to any particular group.

It might seem that reversal theory takes us back to the origins of psychology in the work of the nineteenth century introspectionists, like Wundt, who saw psychology as the study of mental life. But their way of studying mental life typically involved subjects being required to avoid reference to meaning but being asked to respond to stimuli only in terms of basic shapes, colors, etc. In this way, they hoped to get to the pure experience lying behind such interpretations of stimuli as dogs, houses, and chairs. This is quite different from phenomenology, which is all about meaning - exactly that which is excluded in classical introspection.

Psychology of motivation. It is a long time since motivation was placed at the heart of psychological processes by experimental psychologists and it has been generally downplayed by the development and predominance of cognitive psychology in recent decades. An important contribution to the idea of the significance of motivation in understanding psychological phenomena comes from Murray and the projective test - the TAT - that he developed with Christiana Morgan (Morgan \& Murray, 1935; Murray, 1938). They demonstrate a point that is foundational for reversal theory: that the meanings that we attribute to the situations in which we find ourselves derive largely from our motivations. We see the world in terms of these ongoing motives. Murray and Morgan also saw motivation as consisting of more than biological needs but as going to psychosocial desires as well, such as the need for love, and showed how these could be measured using their ingenious test.

Another, perhaps less well recognized influence on reversal theory in relation to motivation was Isaiah Berlin, the Oxford Historian, and his idea that there are values that are incompatible. In particular, social values, like freedom and justice, are incommensurable, which means that there is no way of deciding between them in any ultimate manner. Each is sui generis, and must be judged in its own terms (Berlin, 1978, 1998). Thus freedom is about release from rules, while justice is about regulation through rules.

Psychological change. An influence on the development of reversal theory in relation to change was the Gestalt reversal phenomenon in perceptual studies, such as the wellknown Necker cube, and figure-ground reversals. When this idea of reversing between opposites was taken up in reversal theory, it applied to motivation rather than perception. Gestalt psychology (in its original 1930s sense, not in its later attempt at reincarnation in the work of Fritz Perls and others) can be seen more generally as an influence. Lewin's Gestaltinspired attempt to map out psychological processes in geometric terms (Lewin, 1935, 1936) and the resulting hope of a "topological psychology" was something of an inspiration to many, although never developed. It can be seen retrospectively as a kind of attempt to develop a form of structural phenomenology.

A much more general influence on reversal theory was that of cybernetics: the study of the principles governing the functioning of dynamic control systems, these being systems that are purposeful over time in that they take corrective action when errors occur. The American mathematician Norbert Wiener (1948) originated the term, and the concepts were developed by such researchers and mathematicians as 
my mentor F.H. George (1959), Grey Walter (1953) and W. Ross Ashby (1956), all of whom were personal acquaintances. My first publications were in this area (e.g. Apter, 1966, 1970). The excitement about cybernetics at the time came from the way in which it showed that certain mechanisms (like homeostasis and negative feedback) applied in the operation of many different apparently unrelated systems, such as missile systems, economic systems, ecological systems, mechanical systems, neural systems - and human motivational systems. It was clearly possible to unravel the complexities of human motivation in terms of some of these very broad ideas (e.g. multistability, regulation versus control, and so on), and the development of reversal theory can be seen as an attempt to apply cybernetics to the psychology of motivation.

\section{Question 4: Is reversal theory scientific?}

Is reversal theory best seen as a paradigm, a falsifiable theory, or a research program? Putting the question this way makes implicit reference to the three major concepts in contemporary philosophy of science, due to Kuhn, Popper and Lakatos respectively. These three concepts are usually presented as alternative ways of looking at, and evaluating, scientific projects, but I believe that all three can be made to apply to different aspects of the same project, and each becomes most appropriate at a given stage of development. Thus Kuhn deals in particular with the starting points of scientific theories - the questions that are asked, the new assumptions made, etc. Popper deals with the testing of the theory and the key place of certainty and falsification in this testing. Lakatos deals with what happens in response to the testing. We can therefore look at reversal theory from the perspective of all three of these major theorists

\section{Thomas S. Kuhn}

Kuhn (1968) sees theories in the context of what he calls "paradigms." A paradigm is a set of laws, theoretical assumptions, available instrumentation, specialist language, etc., that prevail at a particular time in the development of a science. Science progresses in part by work within a paradigm but also, albeit more rarely, by switching from one paradigm to a new one - for example from classical physics to quantum mechanics.

Is reversal theory a paradigm? For Kuhn himself, psychological theories cannot be paradigms, because (among other things) they tend to prevail in parallel rather than making a revolutionary jump from one to another during the course of the development of psychology. But some theoretical approaches do seem to have the other characteristics of paradigms, and have been treated as such in psychology: they introduce new instrumentation, make new assumptions, ask new questions, and so on. Thus psychoanalysis asks about certain pathologies, uses certain techniques (e.g. dream analysis, free association), makes certain theoretical assumptions (such as the existence of the unconscious, and of repression). Learning theory makes another set of assumptions, has a different instrumentation (e.g. rats in mazes), different theoretical concepts (reinforcement, drive, etc). In these terms, reversal theory does indeed constitute a paradigm. It asks its own questions e.g. about the frequency and timing of reversals, uses its own theoretical vocabulary, and introduces new instrumentation (such as state indicators and dominance measures).

The success of a paradigm is indicated by its continuing use. When its credibility is doubted by enough researchers, then the point is reached for a paradigm shift to occur and for the approach to be not so much rejected as abandoned and replaced with something else. After forty years, research on reversal theory is still going strong and there is no sign yet of a paradigm shift among reversal theory researchers away from the theory.

\section{Karl Popper}

Inductive generalizations can never be made with certainty, because the next observation might be an exception. On the other hand, if it is an exception this means that the generalization is not true and this falsity we do know with certainty. So, according to Popper, science advances through refutation rather than confirmation. For something to be scientific it must be open to the possibility of refutation (Popper, 1968).

There are, however, some problems with the falsifiability criterion, even though it tends to be taken uncritically by psychological researchers. In particular, a finding that falsifies a hypothesis can itself, in turn, be falsified. Falsification therefore does not give quite the certainty that one would have liked. This is not just a logical problem. It can arise because it is so difficult to replicate studies in psychology. Sometimes an effect is shown and sometimes not (e.g. the Milgram obedience study). Does this mean that if some studies support and some refute a hypothesis that it must be rejected? This does not seem right, especially if it is supported more often than it is rejected. The operationalization of hypotheses invites this to happen. When things are made concrete for testing, it is always possible that they could have been made concrete in a different way. For example, if a hypothesis involves some personality trait and it does not turn out as expected when tested, it could always be argued that the personality test was invalid, or unreliable, or not appropriate for the sample used, and a different one should have been used.

A further problem is that some hypotheses in science are simply about the existence of something, for example the Missing Link, the Higgs-Boson particle, tool-making by dogs. Some reversal theory hypotheses are like this (e.g. 
cognitive synergy). Furthermore, because the existence of something is not found, it does not mean that it never will be. Falsification in this respect is necessarily temporary and tentative.

Having said all that, falsifiability is the best criterion we have for something being scientific, and we should therefore aim to bring it to bear as far as we can on our research and to maintain it as a methodological ideal towards which we should aim. On the whole, reversal theory research has striven towards this ideal, but it is sometimes difficult to apply where some variables are subjective. On the other hand, reversal theory research is no less problematic in this respect than psychometric research in general, since the latter also typically involves questionnaires that involve self-referential and subjective judgments by respondents.

\section{Imre Lakatos}

Like Kuhn, Lakatos (1976) suggests that the progress of science, and the processes that lead to the retention or abandonment of some theories, is based on the judgment of the scientist - not the Popperian ideal of science as a kind of impersonal logic. This leads him to recognize certain complexities in relation to falsification. According to Lakatos, the scientist can try to save his theory in the face of problems, including data that does not fit, and there are legitimate methods for doing so. These methods that can save theories that are still worth keeping in play. For example, Newton's gravitation theory seemed to be falsified early on by its failure to accurately predict the orbit of the moon, but was saved by reference to the inaccuracy of telescopes and other factors such as the spin and wobble of the earth, and the need to treat the moon in calculations as a sphere rather than a point.

For Lakatos, there are two kinds of hypotheses. First there is a "hard core" of propositions that, if definitively falsified, must lead to the rejection of the theory. But there is also a "protective belt" of "auxiliary hypotheses" that can be used to protect hard core hypotheses. These may make the theory more complex, but they may also save theories that later, when given the chance to develop, turn out to have value, and that would have been lost without such protection. To give a psychological example, instinct theory of the nineteen twenties went overboard in adding new "auxiliary" instincts to explain unexpected animal behaviors, but later these formed the underpinning of ethological research and the theories of Lorenz and Tinbergen.

An example of an auxiliary hypothesis in reversal theory is the concept of "shimmering." Some people have reported that they experience both opposites in a pair of motivational states at the same time. For example they say that they have been serious and playful at the same time. This would seem to falsify the hypothesis that only one state from each pair can be active at a time. So the auxiliary hypothesis has been suggested that what is really happening in such rare cases is that the individual is in fact experiencing very rapid alternation between the two opposites, so that at any given instant it is difficult for him or her to say which of the two states is active.

Lakatos evaluates a theory not so much in terms of whether it is true or false, as in terms of whether it is generating good - and exciting - research, or not. For this reason, he sees theories as "research programs." The question then becomes: is the research program "progressive" or "degenerating?" Is it leading to new discoveries? Does it lead to new questions? Does it generate new insights? Does it take us in new directions? I think that it can be reasonably claimed that reversal theory is still a progressive research program. The recent advent of reversal theory work on design would seem to be a good example of exciting new directions for the theory (Fokkinga \& Desmet, 2014).

Both Kuhn and Lakatos see that theories need to be evaluated in terms of more than falsifiability. Consistent with this, Cramer (2013) has suggested six criteria for judging theories. These are: comprehensiveness, precisions and testability, parsimony, empirical validity, heuristic value, and applied value. In these terms, he judges reversal theory as it stands at present to be high in comprehensiveness and parsimoniousness but problematic in terms of precision and testability.

\section{Question 5: What's the use of reversal theory?}

What's the point? Reversal theory started in the applied setting of a child guidance clinic and the first ideas came out of the attempt to make sense of what was being observed in that clinic. In this respect, the theory has been an applied theory from the beginning. Here we are faced with the pragmatic criterion, as developed by William James and other pragmatists (James, 1907). This says, essentially, that the truth of something lies in its usefulness, its "cash value" to use James' famous phrase. The question for reversal theory then becomes: does the theory work in practice, does it actually help people? This is more difficult to answer than questions that can be answered by reference to the research literature, because most uses of any applied theory are likely to fail to be properly documented and, in business at least, are often deliberately undocumented through proprietorial restriction and unwillingness to support outcome studies ("if you do not know that this works, what are we paying your for?").

The interaction between pure research and practice is twoway. Practical problems can lead to the most interesting research puzzles and guide research in fruitful ways. Research findings can be found and taken up by practitioners. Today these applications are mainly in management consultancy and the development of leaders and their organizations. It is also used in sports coaching and, most recently, as noted above, in design. It has also, from the beginning, been used in counselling of various kinds. Some of the techniques used 
have been described in the applied chapters in Apter (2001b), although in recent years various new reversal-theory based techniques have been added, often very creatively, by practitioners.

Very often science makes sudden and rapid progress when a new technology is introduced: the telescope in astronomy and later the radio telescope, the microscope and later the $\mathrm{X}$-ray in biology, the collider centrifuge in the physics of subatomic particles, and so on. Psychology is about to be affected by the wearable technology that is coming on the market. And reversal theory is, beyond any other theory, the one that stands to take most advantage from this technology, since this technology is all about change over time and what is called "ecological momentary assessment" (Mehl \& Conner, 2012). Reversal theory has given rise to studies of this kind for many years (eg. studies of smoking cessation, summarized in O'Connell \& Cook, 2001) and now stands poised to use these new digital recording devices. There is even a general-purpose state measure just waiting to be used in this medium (Desselles, Murphy, \& Theys, 2013).

\section{Question 6: What does reversal theory potentially add to psychology?}

Taking a larger view of the question, we could ask "What does reversal theory have to offer to psychology in general?" Here, in summary, are some brief answers. Some of these have been discussed at more length in Apter, 2001b, pp. 301317.

- A new emphasis on change and instability.

- A new kind of change - reversal - to add to learning and maturation, the two kinds of change previously studied or used as explanation in most psychological research.

- A new level of analysis, somewhere between traits and emotions as traditionally conceived.

- A set of new concepts, especially the concept of reversal itself, but including protective frame, chronotyping, psychodiversity, reversibility, etc.

- The integration of biological and social approaches, both being legitimate in reversal theory terms. If it is true that psychology is beginning to polarize between neurology and discursive/cultural psychology, reversal theory fits into the gap that is widening between them.

- The explanation of paradoxical behaviors: gratuitous risk-taking, humor, etc.

- Practical interventions that do not depend on labeling and therefore limiting people.

- The identification of some key moderator variables that can be discerned in almost any area of psychology, but have not previously been used in research.

- A new type of intelligence - motivational intelligence.

- An emphasis on intra- rather than inter-individual differences and personality as being about patterns over time.
This chapter has taken a broad view of reversal theory and shown how it fits into the "big picture' not only of the psychology of personality, and its history, but also of psychology in general and of the philosophy of science. It is hoped that this will make clearer to those coming to the theory for the first time what its distinctive characteristics are and what it might have to offer them, whether they are researchers or practitioners.

\section{References}

Apter, M.J. (1966). Cybernetics and development. Oxford: Pergamon Press.

Apter, M.J. (1968). The computer simulation of behavior. London: Hutchinson.

Apter, M.J. (1981). Experiencing motivation: Twelve propositions from reversal theory. Self and Society, 9(5), 209220.

Apter, M.J. (Ed.). (1982). The experience of motivation: A theory of psychological reversals. London: Academic Press.

Apter, M.J. (2001a). Reversal theory as a set of propositions. In Apter, M.J. (Ed.), (2001b) Motivational styles in everyday life: A guide to reversal theory (pp. 37-51). Washington, D.C.: American Psychological Society.

Apter, M.J. (Ed.). (2001b). Motivational styles in everyday life: A guide to reversal theory, Washington, DC: American Psychological Society.

Apter, M.J. (2005). Personality dynamics. Loughborough UK: Apter International.

Apter, M.J. (2013). Developing reversal theory: Some suggestions for future research, Journal of Motivation, Emotion, and Personality, 1, 1-8.

Ashby, W.R. (1956). An introduction to cybernetics, London: Chapman \& Hall.

Berlin, Isaiah (1978). Concepts and categories: Philosophical essays, London: Hogarth Press.

Berlin, Isaiah (1998). The proper study of mankind: An anthology of essays, New York: Farrar, Straus \& Giroux.

Cramer, K. M. (2013). Six criteria of a viable theory: Putting Reversal theory to the test. Journal of Motivation, Emotion, and Personality, 1, 9-16.

Desselles, M.L., Murphy, S.J., \& Theys, E.R. (2013) The development of the Reversal Theory State Measure. Journal of Motivation, Emotion, and Personality, 2, 10-21.

Feyerabend, P.K. (1975). Against method. London: New Left Books.

Fokkinga, S. \& Desmet, P. (2010). Reversal theory from a design perspective. Journal of Motivation, Emotion, and Personality, 2, 12-26.

George, F.H. (1959). Automation, cybernetics and society, London: Leonard Hill. 
Hull, C. L. (1952). A behavior system: An introduction to behavior theory concerning the individual organism. New Haven: Yale University Press.

Husserl, E. (1967). Cartesian meditations, The Hague: Nijhoff.

Husserl, E. (1977). Phenomenological psychology, The Hague: Nijhoff.

James, W. (1890). Principles of psychology. Cambridge, MA: Harvard University Press.

James, W. (1907). Pragmatism: A new name for some old ways of thinking. New York: Longmans, Green and Co.

Kuhn, T.S. (1970). The structure of scientific revolutions, Chicago: University of Chicago Press.

Lakatos, I. (1976). Proofs and refutations. Cambridge: Cambridge University Press.

Levi-Strauss, C. (1966). The savage mind. Chicago: The University of Chicago Press.

Lewin, K. (1935). Dynamic theory of personality, New York: McGraw-Hill.

Lewin, K. (1936). Principles of topological psychology, New York: McGraw-Hill.

Mehl, M.R. \& Conner, T.S. (Eds.). (2012). Handbook of research methods for studying daily life. New York: Guilford Press.
Morgan, C.D. \& Murray, H.A. (1935). A method for investigating fantasies: The Thematic Apperception Test. Archives of Neurology and Psychiatry, 34, 209-306.

Murray, H.A. (1938). Explorations in personality, New York: Oxford University Press.

O'Connell, K. A., \& Cook, Mary R. (2001). Smoking and smoking cessation, Chapter 7 in, Apter M.J. (Ed.), (2001b) Motivational styles in everyday life: A guide to reversal theory (pp. 139-153). Washington, D.C. American Psychological Association.

Perls, F. (1947). Ego, hunger and aggression, New York: Vintage.

Popper, K.R. (1968). The logic of scientific discovery. London: Hutchinson.

Saussure, F. De (1959). The course in general linguistics, London: Philosophical Library.

Walter, W. G. (1953). The living brain. London: Duckworth.

Whitehead, A.N. (1929). Process and reality: An essay in cosmology, New York: Simon \& Schuster.

Wiener, N. (1948). Cybernetics: Control and communication in the animal and the machine. Cambridge, M A: MIT Press. 